\title{
Pais e filhos em dois livros franceses de literatura infantil
}

\author{
Parents and children in two french books of children's literature \\ Padres e hijos en dos libros franceses de literatura infantil
}

\author{
AdRiANA PASTORELlo BUim ARENA* \\ DAGOBERTO BUIM ARENA**
}

\begin{abstract}
RESUMO - Como ensinar seus pais a gostar de livros para crianças, de Alain Serres e Bruno Heitz e $O$ que é um bom livro?, de Emmanuel Parmentier, são dois livros franceses destinados, aparentemente por seu formato físico, a crianças, mas, pelo tema, são destinados a pais. Antes de analisá-los, o trabalho refaz um breve percurso sobre o conceito de infância com Ariès e Leontiev e destaca o papel do outro bakhtiniano na constituição do sujeito. As obras defendem o ponto de vista de que os gestos culturais criados para ler literatura infantil devem fazer parte da cultura de relações entre adultos e crianças.
\end{abstract}

Palavras-chave - Literatura infantil francesa. Conceito de criança. Leitura na família. Formação do leitor.

\begin{abstract}
How to teach your parents to love books for children, Alain Serres and Bruno Heitz and What is a good book? Emmanuel Parmentier, are two French books for apparently for its physical format, the children, but the theme is for parents. Before analyzing them, the work retraces a brief passage about the concept of childhood with Ariès and Leontiev and highlights the role of the other Bakhtin in the constitution of the subject. The books advocate the view that the cultural gestures created to read children's literature should be part of the culture of relations between adults and children.
\end{abstract}

Keywords - Children's literature French. Concept of child. Reading in the family. Formation of the reader.

RESUMEN - Cómo enseñar a sus padres a amar los libros para niños, de Alain Serres y Bruno Heitz, y Lo que es un buen libro?, de Emmanuel Parmentier, son dos libros franceses, que en su formato físico podrían ser para los niños, pero sus temas están dirigidos a los padres. Antes de analizarlos, el artículo ofrece un breve comentário sobre el concepto de infancia con Ariès y Leontiev y pone en relieve el papel de lo Otro bakhtiniano en la constitución del sujeto. Las obras defienden la idea de que los gestos culturales diseñados para leer la literatura infantil deben ser parte de la cultura de las relaciones entre adultos y niños.

Palabras clave - Literatura infantil francesa. Concepto del niño. Lectura en la familia Formación del lector.

\footnotetext{
*Doutora em Educação pela Universidade Estadual Paulista Júlio de Mesquita Filho (Rio Claro, SP, Brasil) e professora na Universidade Federal de Uberlândia (Uberlândia, MG, Brasil).E-mail: < dricapastorello@gmail.com>.

**Doutor em Educação pela Universidade Estadual Paulista Júlio de Mesquita Filho (Rio Claro, SP, Brasil) e professor na Universidade Estadual Paulista Júlio de Mesquita Filho (Marília, SP, Brasil).E-mail: <dagobertobuim@gmail.com>.
} 


\section{INTRODUÇÃO}

O debate central neste artigo elege a influência de mudanças no conceito de infância para a entrada no mundo da escrita, por meio da literatura infantil, da criação de livros para crianças e do modo como o livro pode circular nas relações entre pais e filhos. A maneira como a infância é concebida pela sociedade pode interferir radicalmente nas decisões comerciais de livreiros, nos procedimentos metodológicos de professores e na formulação de políticas públicas de diferentes esferas governamentais. Todas essas ações integradas promovem a disseminação do livro, ampliam o desenvolvimento intelectual do homem na idade infantil e estabelecem novas situações ainda inexploradas nas relações familiares.

A pressão social contemporânea exercida pelas instituições sociais em direção à família para promover a entrada precoce da criança no mundo da cultura escrita tem utilizado a literatura infantil como instrumento importante dessa promoção, tanto no seio das relações familiares quanto no interior da escola. Às situações sociais indicativas de alterações profundas no conceito de infância aliam-se as situações das políticas educacionais, como a antecipação da escolaridade formal e a obrigatoriedade da inclusão de crianças de quatro anos em escolas de educação infantil.

Nesse cenário de crescimento da produção, do consumo da literatura infantil como mercadoria e como porta de entrada situada nas porosas fronteiras entre o mundo oral e o mundo escrito, cabem as análises que serão feitas, neste trabalho, de dois livros de literatura infantil, publicados na França. Direcionados estes ,de modo ambíguo, mas deliberado, a filhos e a pais.

\section{UM BREVE PERCURSO HISTÓRICO SOBRE O CONCEITO DE INFÂNCIA}

Para início desta reflexão, serão comentadas algumas contribuições de Badinter (1985), Ariès (1986), e Leontiev (1978), sobretudo as que cuidam da evolução do conceito de infância. A iconografia apresentada desde a Idade Média até o século XVII, quando a representação da criança começa a ser registrada com mais frequência, tornou-se fonte de pesquisa relevante, por ser inédita no campo dos estudos históricos. O recorte anunciado da obra de Ariès (1986) tem a intenção de rever a evolução histórica do conceito de infância, para compreender que o conceito moderno não é formulado naturalmente, antes cultural, histórica e socialmente. Sua existência depende da composição e entrecruzamento de pensamentos políticos, sociais e religiosos modificados ao longo dos séculos pela própria evolução das mentalidades e das relações humanas. Uma vez que nem sempre a criança fora reconhecida ou considerada como parte integrante do corpo social, como um ser da espécie, dotado de características próprias, de sensibilidade e de emoção e, $a$ fortiori, não haveria a necessidade de cuidados especiais de acordo com o seu desenvolvimento.

Segundo Ariès (1986), há indícios, em quadros de pintores, de que a criança não ocupava lugar de destaque nas organizações sociais. A iconografia de natureza histórica revela os modos de viver do homem e das crianças de diferentes épocas e indica os caminhos para a análise das concepções subjacentes a essa representação. As concepções religiosas sobre a origem dos homens e as concepções científicas sobre a natureza humana nem sempre favoreceram o olhar cuidadoso do adulto dirigido para esse período bem específico e fundamental da vida do ser humano como elo da espécie. Conforme Ariès (1986, p. 28),

\begin{abstract}
foi no século XVII que os retratos de crianças sozinhas se tornaram numerosos e comuns. Foi também neste século que os retratos de família, muito mais antigos, tenderam a se organizar em torno da criança, que se tornou o centro da composição. [...] A descoberta da infância começou sem dúvida no século XIII, e sua evolução pode ser acompanhada na história da arte e na iconografia dos séculos XV e XVI. Mas os sinais de seu desenvolvimento tornaram-se particularmente numerosos e significativos a partir do fim do século XVI e durante o século XVII.
\end{abstract}

É possível perceber que o autor não estabelece uma data fixa para a modificação das mentalidades. Pelo contrário, registra que foi necessária uma longa evolução histórica para que outro conceito as impactasse. O fato de concluir que no século XVII os adultos modificavam sua concepção marcada por atenção, não concedida anteriormente, não significa dizer que dedicassem às crianças um lugar privilegiado nas relações familiares.

Outra evidência de que ao longo da história a criança foi rejeitada como ser social está presente no pensamento de Santo Agostinho, que seduziu educadores por muito tempo na história da pedagogia. Nas palavras de Badinter (1985, p. 55),

durante longos séculos, a teologia cristã, na pessoa de Santo Agostinho, elaborou uma imagem dramática da infância. Logo que nasce a criança é símbolo da força do mal, um ser imperfeito esmagado pelo peso do pecado original. Em A cidade de Deus explicita longamente o que entende por "pecado da infância" [...] para Santo Agostinho, a infância é o mais forte testemunho de uma condenação lançada contra a totalidade dos homens, pois ela evidencia como a natureza humana corrompida se precipita para o mal. 
Hoje, estas palavras portam certa estranheza, mas, naquela época, conduziram a forma de pensar, de sentir e de agir em relação à infância. Se a natureza humana era corrompida, o trabalho de recuperação seria difícil e penoso. Para muitos pedagogos da época, quase sempre mestres em teologia (BADINTER, 1985), cujo ofício era o de promover o resgate dessas crianças perdidas, a palavra educação era utilizada em seu sentido etimológico, do verbo educare, endireitar o que é torto ou malformado.

Para Badinter (1985), na teoria agostiniana, a infância não teria valor, nem especificidade, e seria o indício da corrupção, daquilo que se condena e do qual é preciso se livrar. Em nome desses postulados agostinianos, muitos professores e pais castigaram seus filhos com a finalidade de educá-los, pois o castigo tinha um papel importante para salvar a alma dos vícios e dos defeitos.

Badinter (1985, p. 62) observa que, após longo tempo de ressonância das palavras de Santo Agostinho, ecoaram, no séc. XVII, as palavras de Descartes:

[...] a infância é antes de mais nada fraqueza do espírito, período da vida em que a faculdade de conhecer, o entendimento, está sob a total dependência do corpo. A criança não tem outros pensamentos senão as impressões suscitadas pelo corpo. O feto já pensa, mas esse pensamento não passa de um magma de idéias confusas. Desprovida de discernimento e de crítica, a alma infantil se deixa guiar pelas sensações de prazer e de dor: está condenada ao erro perpétuo.

Mais uma vez, a infância é concebida como o período da vida humana que deve ser esquecido para permitir ao homem o alcance da racionalidade e da verdade absoluta. O que importa notar é que, seja o pecado ou o erro, a infância era compreendida como um mal a ser corrigido rigorosamente.

Ariès (1986), na conclusão de sua obra, reproduz a letra de uma canção escrita por Coulanges (Chansons Choisies, 1694) que representa o sentimento de algumas pessoas que viveram no final do século XVI e, sobretudo, no século XVII, em relação à mudança do conceito de infância. Período em que a criança passou a ser reconhecida como parte integrante da sociedade e como um ser dotado de características humanas. Os resquícios daqueles que não concordavam com a mudança de visão em relação a isso se manifestavam das mais diversas formas. Eis a canção:

Para bem educar vossas crianças

Não poupeis o preceptor

Mas, até que elas cresçam

Fazei-as calar quando estiverem entre adultos

Pois nada aborrece tanto

Como escutar as crianças dos outros.
O pai cego acredita sempre

Que seu filho diz coisas inteligentes,

Mas os outros, que só ouvem bobagens

Gostariam de ser surdos

E, no entanto, é preciso

Aplaudir o enfant gâté.

Quando alguém vos disser por polidez

Que vosso filho é bonito e bem comportado

Ou the der balas

Não exijais mais nada

Fazei vosso filho assim como seu preceptor

Agir como um servidor.

Ninguém acreditaria que uma pessoa de bom senso

Pudesse escrever

Para criancinhas de três anos

Se as de quatro não sabem ler.

No entanto, há pouco tempo

Vi um pai entregue a essa tola diversão.

Sabei ainda, caros amigos

Que nada é mais insuportável do que ver vossos filhinhos

Pendurados na mesa como uma réstia de cebolas

Moleques que, com o queixo engordurado

Enfiam o dedo em todos os pratos.

Que eles comam em outro lugar

Sob as vistas de uma governanta

Que lhes ensine a limpeza

E não seja indulgente

Pois não se pode com rapidez

Aprender a comer com limpeza

(COULANGES, 1694 apud ARIÈS, 1986, p. 1020).

(Grifos dos autores).

O primeiro ponto a ser ressaltado em relação a esta composição é que nela apresenta-se a ideia, que perdura até hoje, de separar o mundo das crianças do mundo dos adultos. E o segundo aspecto que merece atenção está centrado no próprio discurso sobre a infância. Ao mesmo tempo em que a canção faz uma crítica aos adultos que dão atenção às crianças, também revela a sua presença em situações que antes não eram permitidas. Assim, podese perceber um conflito de posições entre um momento histórico em que a infância era vista como uma fase sem importância e outro que começa a reconhecê-la como participante da rede social.

A insignificância do tratamento dedicado está presente na literatura. Para o pensamento da época, a criança não conseguiria manter atenção durante a leitura de uma história. Um exemplo disso é o baixo número de títulos publicados no período Medieval, e até mesmo no Moderno. La Fontaine (1621-1695), ao evocar temas infantis, deseja mais rivalizar-se com o poder de censura 
da época do que necessariamente escrever às crianças, pois escrever fábulas era uma atividade de pouco prestígio.

Leontiev (1978, p. 270), por seu turno, salienta que as aptidões e os caracteres especificamente humanos não são herdados geneticamente, mas conquistados no decorrer da vida do indivíduo por meio de um processo de apropriação da cultura criada e ensinada pelas gerações precedentes:

A criança não está de modo algum sozinha em face do mundo que a rodeia. As suas relações com o mundo têm sempre por intermédio a relação do homem aos outros seres humanos; a sua atividade está sempre inserida na comunicação. A comunicação, quer esta se efetue sob a sua forma exterior, inicial, de atividade em comum, quer sob a forma de comunicação verbal ou mesmo apenas mental, é condição necessária e específica do desenvolvimento do homem na sociedade.

Volta-se, assim, ao primeiro ponto destacado: não há como separar o mundo dos adultos do mundo das crianças. É possível inferir que se torna essencial o seu engajamento cultural, pois o "aprendizado pelo engajamento nas demonstrações de outros é um modo particularmente eficiente e econômico de as crianças aprenderem, porque limita a possibilidade de erros ou incertezas" (SMITH, 1989, p. 229). Os gestos de Chartier (2001) ou as demonstrações de Smith (1989) são os atos históricos, culturais e sociais, apropriados e objetivados pelas crianças nas relações com as demais e com os adultos mergulhados no caldo cultural de uma mesma época.

A canção citada por Ariès (1986) prescreve aos pais as condutas necessárias para a separação entre os dois mundos - o do adulto e da criança - com a consequente exclusão da possibilidade de apropriação de gestos importantes, entre eles o de ler. As crianças não tinham o direito de falar com o adulto, de fazer suas refeições à mesa com os demais, de realizar leituras ou ouvi-las pela boca dos pais. Ao colocar a criança de quatro anos ou de três no papel social do outro (BAKHTIN, 2003), o pai poderia receber o julgamento condescendente de tolo ou, mais severo, de lunático. Na segunda década do século XXI, a prescrição é extraordinariamente a oposta: é preciso escrever e ler para as crianças para que elas possam se apropriar do gesto cultural, do ato de ler, do ato de escrever, da modalidade escrita de linguagem, em toda a sua potencialidade como instrumento cultural e social de formação filogenética do homem. Em vez de tola diversão, escrever para a criança e com ela, trocar enunciados em situação dialógica (BAKHTIN, 2003), colocar-se na posição do outro que aceita, contesta e amplia, tornou-se uma atividade necessária na atividade humana deste século. Desse modo, desprovidas do direito de viver em comunhão com os demais seres de sua espécie, são privadas do direito de desenvolver-se plenamente como um ser na relação com as palavras alheias, como explica Bakhtin (2003, p. 379):

Eu vivo em mundo de palavras do outro. E toda a minha vida é uma orientação nesse mundo; é reação às palavras do outro (uma reação infinitamente diversificada) a começar pela assimilação delas (no processo de domínio inicial do discurso) e terminando na assimilação da riqueza da cultura humana (expressas em palavras ou em outros materiais semióticos).

A relevância da apropriação da palavra do outro no domínio do discurso e na assimilação da riqueza humana, preconizada por Bakhtin em meados do século XX, opõe-se à prescrição popular da canção do final do século XVII, reveladora da mentalidade sobre a infância e sobre o seu desprestígio na formação do indivíduo. Sintonizase com as prescrições dos livros de literatura infantil, que adiante são apresentados, escritos para crianças e pais, os outros do processo dialógico. A origem das mudanças no desenvolvimento individual vincula-se às relações entre sujeito, sociedade, cultura e história de vida, além das oportunidades e das situações de aprendizagem que promovem esse desenvolvimento (VIGOSTKY, 2001). Utilizando-se de diferentes instrumentos da cultura e da história, que promovem o desenvolvimento das funções mentais superiores. Portanto, o desenvolvimento do indivíduo e suas interações com o outro são necessárias e fundamentais, porque delas são criados os signos, os gêneros do discurso - entre eles, a literatura infantil, portadora de cultura - e a criação da apreciação estética. Ao comentar estudos de Bakhtin a respeito da literatura e de sua importância para o homem, Arena enfatiza que

o leitor pequeno, pela literatura infantil apropria-se da cultura do outro. Por meio dessa literatura, apropriase das palavras embebidas culturalmente e, com elas, forma a sua própria consciência, porque 'a compreensão de uma obra em uma língua bem conhecida (ainda que seja a materna) sempre enriquece a nossa compreensão de tal língua como sistema' (BAKHTIN, 2003, p. 316). (ARENA, 2010, p. 21).

É sob essa perspectiva que o próximo tópico apresenta dois livros franceses de literatura infantil portadores de algumas provocações possíveis nas conturbadas, difíceis e estranhas prescrições da velha canção seiscentista, e de outras aproximadas da oxigenada concepção de infância dos tempos atuais e de sua relação com a literatura infantil.

\section{O LIVRO PARA A CRIANÇA}

Ao entender o processo histórico pelo qual passou a construção do conceito de criança, é possível 
compreender que pouca atenção foi dada à voz infantil, acostumada a obedecer e a calar. Nesse quadro, criar histórias e, portanto, literatura para crianças, seria uma ação revolucionária, por ignorar o contexto social de uma época para, em contrapartida, inseri-la em um futuro com configuração pouco vislumbrada em séculos anteriores. Entretanto, se estão razoavelmente delineados os contornos de um mundo em que a criança tomou a sua voz e ocupou lugares importantes nas relações sociais, não estão consolidados, apenas com a criação da literatura infantil e com a produção abundante de livros, os gestos culturais de leitura entre os pequenos. Podem-se destacar duas razões, entre outras, para explicar esse fenômeno. A ausência dos mesmos gestos entre pais, de qualquer que seja o segmento social, isto é, a inexistência da sua forma ideal, como aponta Vigotsky (2001), no entorno cultural, ou, ainda,o não reconhecimento de pais e educadores a respeito do impacto da literatura infantil na formação da consciência e da cultura escrita.

Os dois livros franceses, destinados a crianças, aparentemente por seu formato, mas fundamentalmente para pais por seu conteúdo, defendem, como pode ser observado nos próximos tópicos, o ponto de vista, nos anos correntes, da importância dos gestos culturais criados durante $o$ ato de ler literatura infantil. Por essa razão, os livros fazem parte da cultura de relações entre adultos e crianças: ensinar a ler literatura infantil e ler com as crianças os livros a elas destinados é ver a criança no mundo humano que não se limita à concessão do abrigo, da alimentação saudável, das vestimentas e do conteúdo escolarizado, mas que se estende ao mundo da cultura escrita e da palavra do outro.

Como ensinar seus pais a gostar de livros para crianças (SERRES; HEITZ, 2008) e O que é um bom livro? (PARMENTIER, 2009) são duas obras provocativas por colocarem o dedo na ferida da mediação cultural há pouco comentada. O primeiro, abusada e tacitamente, parte do pressuposto de que os pais devem aprender a ler os livros que compram para os filhos, ou que os filhos tomam por empréstimo das bibliotecas escolares, das públicas ou da biblioteca do melhor amigo. Não parece ser pouco, no mundo em que o conceito de infância se amplia, o fato de o adulto ler para os pequenos. O gesto essencial, a forma ideal, é a de que as crianças devem ler os livros que foram criados e formatados intencionalmente para elas, com a mediação do adulto, porque apropriar-se da literatura infantil é apropriar-se dos conceitos e da cultura da infância em transformação.

No segundo livro, Lucas, abraçado a sua pergunta - "o que seria um bom livro para presentear o pai?" -, percorre o caminho entre sua casa e a livraria. Não sem antes lançar a sua pergunta para adultos, de seu pequeno mundo, ou aos de fora dele, na mais direta exposição do dialogismo bakhtiniano em que o outro, adulto, sente-se acuado dentro de seu limitado universo da cultura ou da questão inusitada, por isso perturbadora.

Os dois livros franceses, ao mesmo tempo em que cumprem sua função literária, também apresentam a discussão que os estudiosos da infância e da literatura infantil a si mesmo se põem: qual seria a melhor maneira de proporcionar o encontro da criança com a leitura e que escolhas fazer no grande mercado de literatura em crescimento? Em vez de artigos acadêmicos, os dois livros parecem indicar, pela própria natureza inacabada da formação e da cultura humanas, as respostas possíveis e inconclusas.

\subsection{O primeiro livro}

A dupla intenção de atingir dois grupos de leitores, pais e crianças, torna a obra uma criação surpreendente ao ensaiar a subversão da relação histórica entre quem ensina e quem aprende o gesto, o ato cultural de ler. Apesar de ser infantil no formato e no tema, o livro provoca o adulto, como o casal de pesquisadores brasileiros, autores deste artigo, em visita ao Museu da Imprensa, em Lyon, França, no final de 2010. Ao ler o título do livro, os pais, em verdade, leriam outro título, de caráter impositivo, subjacente ao apresentado na capa: "Compre e leia este livro para não descuidar da educação cultural de seus filhos. Depois de lê-lo, leia para seu filho, leia com seu filho, e lhe entregue para que o leia, se quiser. E depois de ler este, compre outros e tenha o mesmo procedimento: leia o livro do filho, leia com ele e para ele e ofereça-o para compor a biblioteca pessoal dele. Pelos livros de literatura, seu filho entrará no mundo da cultura escrita".

Ao colocar os pequenos no papel de orientadores, ou de quem assume a conduta de convencer o outro, historicamente superior, sobre uma conduta considerada nobre, Serres (2008) abala o conceito de infância por conceder à criança a prerrogativa de orientar os pais, supostamente avessos, não somente no Brasil, mas também em países como a França, para a leitura dos livros a ela destinados. Serres (2008) repõe, com um título contundente e com enunciados desconcertantes, o processo de aculturação, de legado da cultura e da ampliação do conceito de infância para além da tutoria adulta: ele dá voz e prestígio à criança nas relações humanas e familiares, sem separar o mundo dos adultos do mundo dos infantes, antes, considera-os como seres embebidos pelo mesmo caldo de cultura.

Formatado em capa dura, o texto apresenta, aparentemente para as crianças, quatorze argumentos que poderiam ser utilizados para abalar as atitudes e comportamentos paternos, cotidianamente entendidos como obstáculos para a mediação da leitura como prática cultural. A estrutura do enunciado se organiza em torno de 


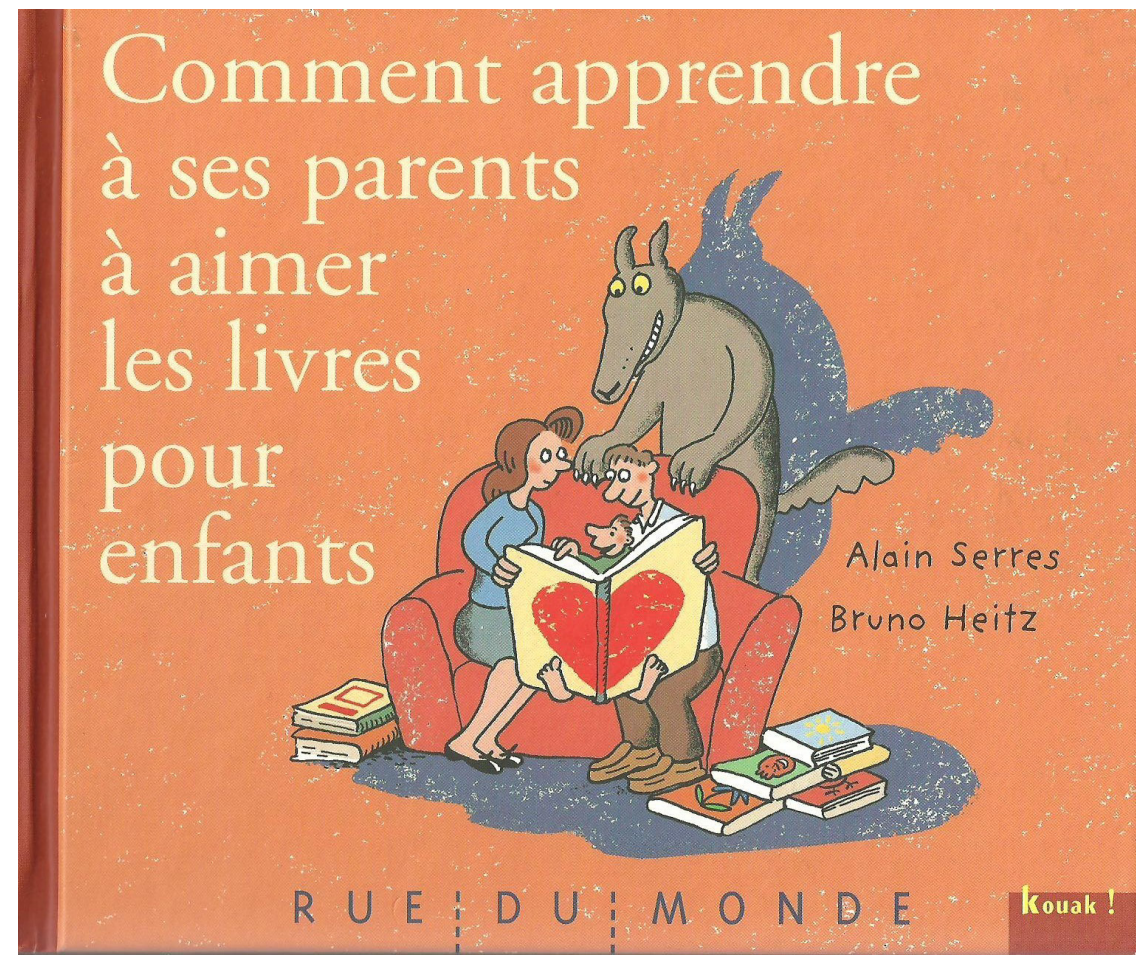

Figura 1 - Capa do livro Como ensinar seus pais a gostarem de livros para crianças, de Alain Serres.

Figura 2 - Quarta capa do livro Como ensinar seus pais a gostarem de livros para crianças, de Alain Serres.

Tradução: Um álbum surpreendente e cheio de ideias para ajudar os pequenos leitores a dizer aos adultos como ler lhes faz bem. E, também, como há emoções entre as páginas dos bons livros para crianças, para a felicidade dos pequenos... e também dos pais.

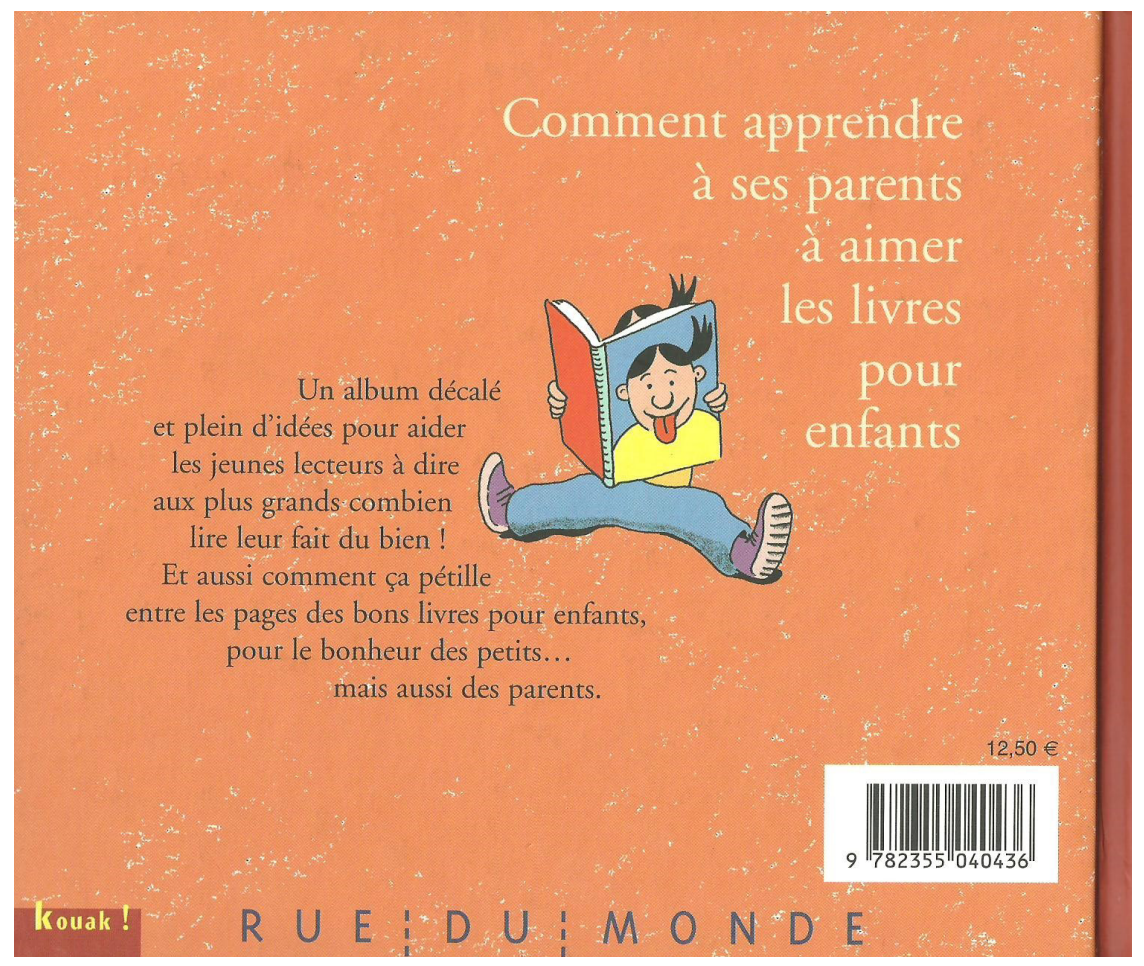

uma hipótese inicial, com o uso da conjunção condicional se, acompanhada de outro enunciado de natureza prescritiva. Dois desses conjuntos (o primeiro e o último) articulados são aqui escaneados e comentados com o intuito de preservar o texto de Alain Serres, sua formatação e sua articulação com as ilustrações de Bruno Heitz.

Perspicaz, Serres (2008) endereça o enunciado para as crianças que podem alimentar medo de lobos, ao mesmo tempo em que lhes dá a coragem de assumir o papel de guardiões dos pais por serem experientes em lobos, em seu mundo de leitores, mais do que os adultos. Ao apresentar à criança o medo suposto que pais podem ter das coisas, dá-lhes a condição de que podem orientar, tranquilizar e abrigar pais indefesos e amedrontados. A genialidade do enunciado de Serres (2008), complementada com a ilustração de Heitz, impacta de modos diferentes os dois leitores, 
em relação de trocas culturais, curiosamente amalgamadas no verbo francês apprendre. ${ }^{1}$ Entre os quatorze argumentos que se referem a situações comuns no seio familiar, um deles revela a despreocupação dos pais diante do interesse do filho em penetrar no mundo da cultura escrita: "Se os teus pais permanecem até tarde na cama, no domingo de manhã, em lugar de ler a pilha de livrinhos que você preparou na véspera, diga-lhes que nos livros também há carícias ternas e deliciosas". E outro os remete para a brutalidade da vida: "Se teus pais detestam quando um bichinho passeia em um livro com cocô sobre a cabeça, explique a eles que você já viu coisa pior na Rua-da-Verdade: um homem dormindo, de verdade, perto de uma lixeira".

A infância, mais crítica no livro de Serres (2008), leva as crianças a discutir com os pais o direito de ver a porta aberta para que possam ensaiar a transição entre a cultura do oral para a cultura da escrita. O tema destacado só pode ter origem em contextos sociais em que os pais não dão atenção ao ato cultural de ler literatura infantil para seus filhos e com eles e o desqualificam como ato que transcende e supera as atividades escolares nas quais as crianças nem sempre encontram sentido.

Fijalkow (2000) analisa os dados indicadores do fracasso escolar de alunos franceses no campo da leitura, no final dos anos 1990, na França. Frequentemente, as ações de superação desse fracasso são dirigidas para as consequências em vez de tocar nas causas. Entre elas, segundo entende, está a resistência da criança em adotar a cultura do outro para, como contrapartida, ter de abandonar a sua e a de seus pais. De outra parte, pais temem que seus filhos abandonem sua cultura, num gesto típico de traição a eles e ao que representam. A decisão de não ler para os filhos e com eles pode revelar o temor pela sua perda, porque os encaminham aos braços da cultura do outro; enquanto eles, pais, antes sábios, passam à condição de inferiores por viverem mais próximos do mundo oral e do trabalho diário. Deixar de ler, desse modo, não é senão uma atitude de resistência e de proteção à cultura familiar e à de seus membros, contra o ataque da cultura do outro que usa as crianças como agentes de sabotagem.

Mais do que seres em formação, as crianças, na infância do século XXI, tornam-se, ao entrar no mundo da cultura escrita, o outro bakhtiniano nas relações dialógicas. São como um nó em redes construídas pelos adultos e por elas próprias, por meio da modalidade escrita de linguagem. Em vez de aprender inicialmente as relativas, precárias e instáveis relações fonema-grafema, para somente mais tarde conquistar o direito de entrar no mundo da cultura escrita, as crianças dessa nova infância entram primeiramente nesse mundo pelas vozes, mãos, olhos e gestos culturais dos pais. E, de dentro deste, começam a elaborar outros conceitos para compreender o funcionamento pleno da linguagem escrita no fluxo vivo das relações humanas. Serres (2008) sugere, ao tomar o ponto de vista das crianças como os responsáveis pela introdução dos pais no mundo da escrita, que esses pais ocupem com convicção o papel de praticantes de atos culturais para ampliar também o universo cultural de seus filhos, em vez de atribuir apenas à escola essa função. Mas qual seria a produção cultural qualificada por meio da qual seus filhos poderiam transitar do mundo oral para o mundo da escrita? A pergunta se encontra com a que

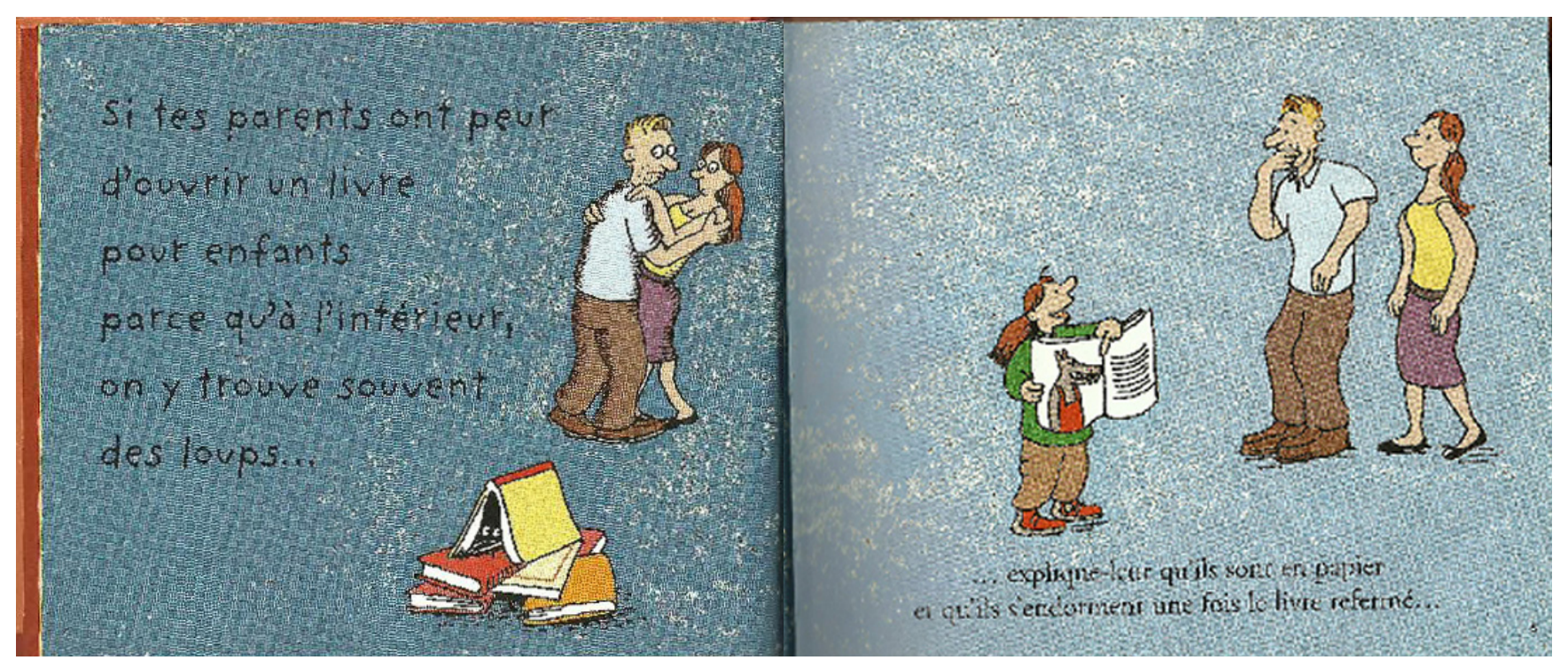

\section{Figura 3}

Tradução: Se teus pais têm medo de abrir um livro para crianças porque em seu interior podem-se encontrar com lobos ... ... explique-lhes que eles são de papel e que eles adormecem assim que o livro é fechado... 
dá título ao texto de Emmanuel Parmentier, ilustrado por Alain Mathiot (2009) - O que é um bom livro?

\subsection{E o é que um bom livro?}

Parmentier (2009) toma como referência para a criação de sua história infantil a situação corriqueira de um aniversário familiar, cuja data pode passar sem ser percebida. A mãe, na cozinha, com os olhos cheios de lágrimas provocadas pelo ardor de cebolas, lembra ao filho, às voltas com a feitura de pequenas tortas, que o pai faria aniversário e mereceria um presente dado por ele. Pressionado pela situação, pediu à mãe um conselho, dado após curta reflexão:

- Você sabe, seu pai foi sempre um grande leitor. Você tem de dar a ele um bom livro. Com isso, você dará prazer a ele.

- Um livro, isso, eu não tinha pensado nisso. Excelente idéia. Sim, mas, um livro, eu sei o que é, sem problemas. Mas e o que é um bom livro? (PARMENTIER, 2009, p. 12). (Tradução dos autores).

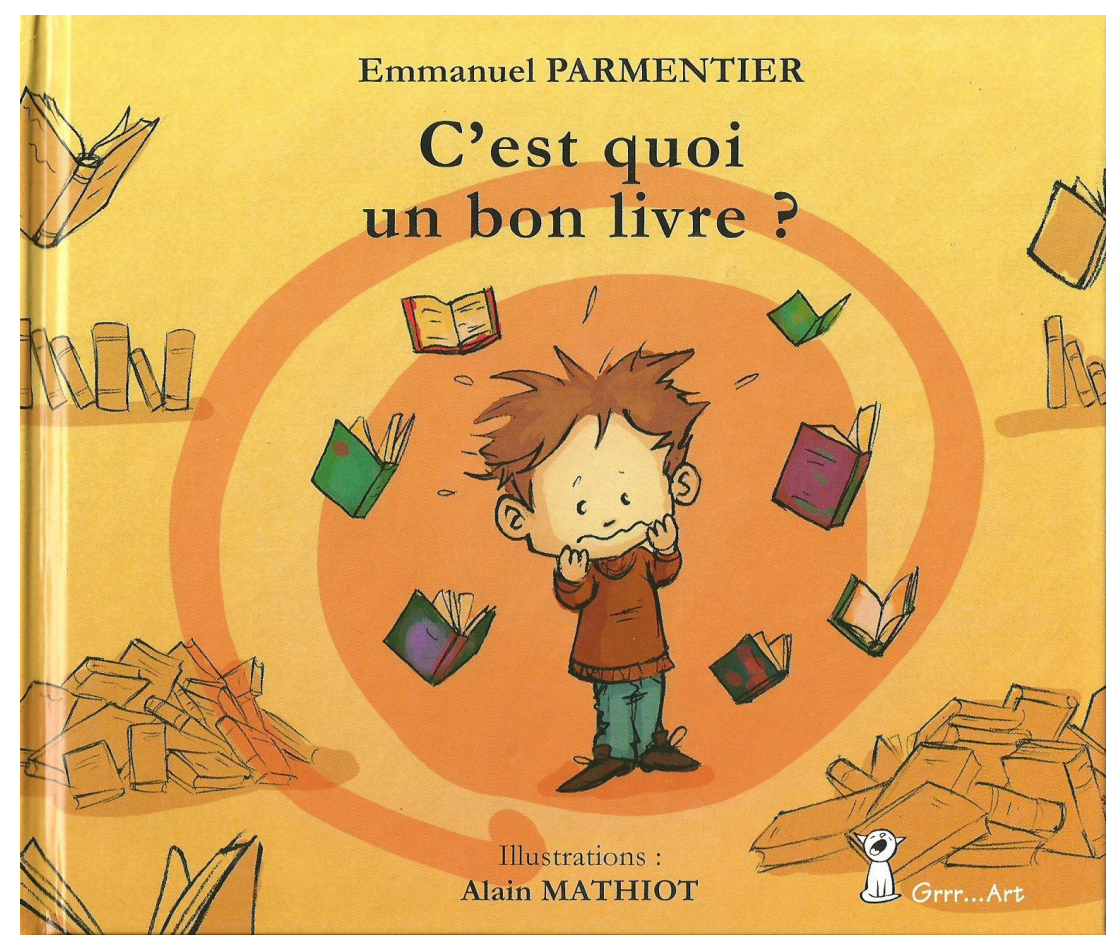

Figura 4 - Capa do livro $O$ que é um bom livro?

Figura 5 - Quarta capa.

Para o aniversário de seu pai, Lucas deve lhe oferecer um bom livro. Sim, mas, veja lá, um livro todo mundo sabe o que é. Mas o que é um bom livro?

Uma engraçada pesquisa tem início para o nosso pobre Lucas...

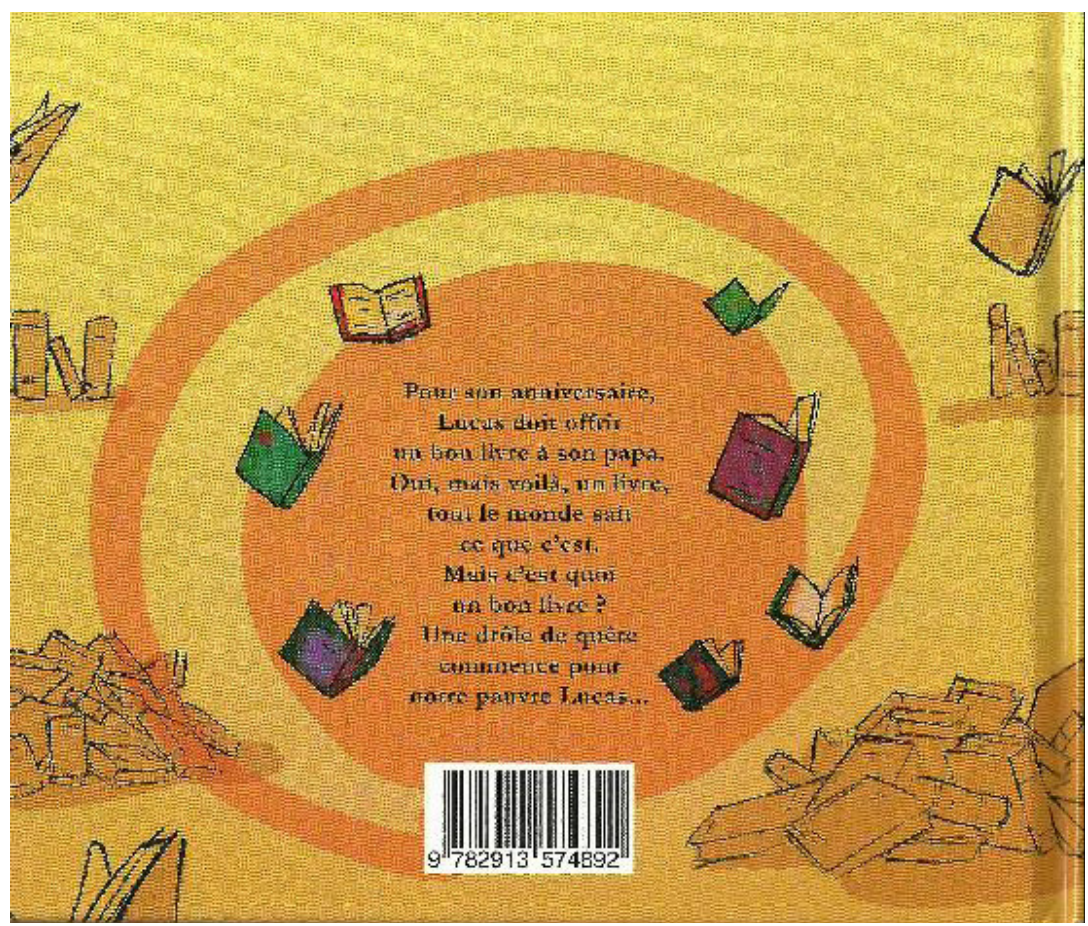


A pergunta colocada na boca do pequeno personagem como um enigma não é senão o mesmo enigma a incomodar professores da academia, professores do ensino fundamental, avaliadores de programas governamentais, consultores de editoras, pais e, agora, crianças! Respostas precisas, seguras e definitivas são oferecidas como protocolos ou gabaritos, especialmente, as que se reportam à qualidade literária, à ousadia das ilustrações e à editoração esmerada. Parmentier (2009) desloca o sempre dilema dos pais em direção ao pequeno Lucas, representante das crianças francesas, alvos das políticas de disseminação da leitura de livros infantis.

Com sua pergunta na ponta da língua, saiu Lucas pelas ruas, porque sua mãe, em casa, não dera conta de dar-lhe a resposta de que precisava. $\mathrm{O}$ homem bem vestido lhe disse que livros para nada servem, aliás, servem para fazer perder tempo; a jovem apressada não pôde lhe responder, porque, agitada, dizia não ter tempo para ler, muito menos à noite, morta de cansaço. O padeiro da vila acreditava que um bom livro deveria ser como um bom pão, que se come ou se lê, sem fome. Do escritor, sentado na praça, rabiscando papéis e tomando café, Lucas ouviu que ele escrevia livros, mas não sabia se eram bons. A pergunta deveria ser dirigida aos seus leitores. Ao vovô surdo, sentado no banco do jardim, a pergunta derivou para a falta de memória dos livros lidos há muito tempo. De um jovem cabeludo, esparramado sobre a relva, ouviu que um livro é o que transporta o leitor para outros tempos, para outros lugares, sem sair do lugar. A senhora com um bebê, um pouco mais além, disse que um bom livro é o que nos toca profundamente. A mocinha vestida de negro, ao pé de uma árvore, com um sorriso estranho, disse a Lucas que um bom livro é o que provoca suspense, que dá frio na barriga. O livreiro apreensivo, mas resignado em razão das baixas vendas, respondeu que um bom livro depende do gosto dos leitores. Parmentier (2009, p. 39) fecha o texto desta forma: "O livro, você o tem entre as mãos. Ele termina assim. E, se você não o achou bom, saiba que também tem o direito de levá-lo a sua livraria".

Os papéis sociais são aqui invertidos: quem presenteia o pai é o filho, e o livro-presente, que algumas crianças recebem a contragosto dos pais, deve ser mesmo um livro, mas não um qualquer, mas de qualidade reconhecida. As obrigações paternas de presentear os filhos com livros, atos recomendados pela mídia, por livreiros e por pedagogos, são deslocadas para o filho, que assume a dura tarefa de escolher um livro qualificado para um pai, leitor exigente, que deveria formar também um filho leitor.

A saga de Lucas desnuda a configuração dos leitores de literatura na França, ao longo de seu trajeto e nos encontros com seus personagens: os nada leitores, os pouco leitores, os leitores específicos de certo gênero e os leitores mais exigentes. Esses leitores ocupam, também, papéis sociais estereotipados com suas vestes e profissões definidas: o padeiro, o escritor, o livreiro; o homem bem vestido, a moça apressada, a moça de negro-gótico, o rapaz cabeludo e o vovô surdo. O livreiro, expert em vendas, fez deslocar a qualidade do livro para fora dele mesmo; em vez de possuir ele próprio as suas qualidades, criadas pelo escritor e pela editoração, são os leitores, cada um a seu modo, os responsáveis pela sua qualificação.

Esse deslocamento traz para Lucas um desafio maior. Se fosse o livro ele mesmo a indicar sua qualidade, bastaria escolhê-lo pelo seu ritmo de vendas, mas, se é o leitor o responsável, o desafio cresce, porque o pai é um leitor sênior, exigente e crítico. É preciso que ele, Lucas, descentralize o ato de escolha do próprio livro, dele mesmo, como presenteador, e o centralize nas exigências do presenteado, seu pai. Essa relação entre pais, filhos, literatura infantil, cultura e escola não assume, para seus integrantes, interações tranquilas entre saberes necessários e culturas respeitadas. Essas relações na França, conforme as vê Fijalkow (2000), não são bem compreendidas, porque parece haver o consenso de que os pais e seus filhos aceitam e respeitam a cultura escolar, isto é, a cultura do outro como a que deve ser por eles assumida, mesmo que o preço a ser pago seja o abandono total ou parcial de sua cultura.

O fracasso na apropriação dos atos culturais de ler ensinados pela escola pode ter uma origem, entre outras, no fato de os pais quererem que seus filhos aprendam a ler, mas que não abandonem a identidade da família a que pertencem.

Os pais estão de acordo com as aprendizagens técnicas, mas técnicas unicamente. A escola, de sua parte, apresenta uma oferta global: ela ensina a ler, mas em certo contexto cultural, indissociavelmente. A aquisição da leitura não vai se dar sem a adesão à cultura veiculada pelos livros (FIJALKOW, 2000, p. 153). (Tradução dos autores).

A reordenação dos papéis entre pais e filhos proposta por Serres e por Parmentier (2009), no intuito claro de alertar os pais para a necessidade de ler para os filhos e com eles, ou de presenteá-los, não considera esse aspecto que compõe o cenário de famílias de imigrantes ou de cidadãos à margem da economia e da cultura francesas, destacado por Fijalkow (2000): o movimento de resistência. Se a qualificação do livro nem sempre está nele mesmo, mas com o leitor, não há, de outra parte, consenso de que a leitura de um livro pelo filho é algo importante, porque esse ato cultural de ler traz consigo a cultura do outro que pode afastá-lo de sua cultura familiar ou de promover o desarranjo da estabilidade das relações do núcleo doméstico. 
Ao ver essas relações por esse ângulo, podem-se entender as intenções de inserir as obras nos movimentos dos livreiros, dos agentes governamentais e escolares para a difusão da leitura de literatura infantil. E, com elas, promover a difusão da língua e da cultura francesas entre os segmentos mais resistentes. Apesar desse movimento, a inserção das crianças no mundo da cultura escrita não se daria, para alguns pais, pela leitura dos livros, mas pela aprendizagem técnica, pela aprendizagem reducionista da relação entre letras e seus fonemas correspondentes. Essa prática reducionista entra como uma luva na mão dos políticos assessorados por segmentos acadêmicos defensores do pressuposto funcionalista de aprendizagem.

\section{ConClusão}

Pode-se delinear, por fim, quatro grandes tendências do uso que se tem feito da literatura infantil nas escolas. O caráter recreativo: ler para a criança com o objetivo de oferecer alternativas prazerosas entre atividades geradoras de tensão; a função pedagógica de ensinar conceitos ou comportamentos físicos, e condutas emocionais e sociais; a aculturação do sujeito por meio do processo de apropriação da cultura do outro, o aspecto menos perceptível, tangível ou intencional no ambiente escolar; a alavanca de emancipação da criança e do homem que virá a ser, processo que para um dos segmentos é percebido como de dominação.

Consideradas as alterações das concepções de infância e as posições sociais que as crianças ocupam, tanto no ambiente familiar quanto fora dele, é preciso reconsiderar, também, os espaços ocupados pelos livros de literatura infantil nas relações professores-alunos, na escola, e nas relações pais-filhos, no ambiente cultural familiar. A literatura resiste à função pedagógica a ela imposta pela cultura escolar e à função ingenuamente recreativa sugerida pela mídia por ser portadora natural de emoções que criam o prazer. Encaixa-se, sobretudo, no debate do amplo tecido social como instrumento de aculturação, de submissão de uma cultura a outra, ou, de outro modo, ganha os contornos de uma ponte que dá suporte à passagem necessária entre os gestos da cultura oral para os gestos da cultura escrita. Mais do que uma simples passagem, abre a criança para um mundo de emancipação de seu espírito, de sua consciência. Os dois livros franceses comentados neste trabalho espelham esse debate, mas, ao mesmo tempo, refletem a reconfiguração das relações da tríade pais-livros-filhos. A escola poderá entrar nessa tríade para compor uma relação quadrilateral.

\section{REFERÊNCIAS}

ARENA, Dagoberto Buim. A literatura infantil como produção cultural e como instrumento de iniciação da criança no mundo da cultura escrita. In: SOUZA, Renata Junqueira de et al. Ler e compreender: estratégias de leitura. Campinas: Mercado de Letras, 2010.

ARIÈS, Philippe. História social da criança e da família. Rio de Janeiro: Guanabara, 1986.

BADINTER, Elisabeth. Um amor conquistado: o mito do amor materno. Rio de Janeiro: Nova Fronteira, 1985.

BAKHTIN, Mikhail. Estética da criação verbal. São Paulo: Martins Fontes, 2003.

CHARTIER, Roger. Cultura escrita, literatura e história. Porto Alegre: Artmed, 2001.

FIJALKOW, Jacques. Sur la lecture: perspectives sociocognitives dans le champ de la lecture. Issy-les-Moulineaux: ESF éditeur, 2000

LEONTIEV, Alexis. O homem e a cultura. In: LEONTIEV, Alexis. O desenvolvimento do psiquismo. Lisboa: Novo Horizonte, 1978. p. 261-281.

QUINTEIRO, Jucirema. Infância e escola: uma relação marcada por preconceitos. 2000. Tese (Doutorado em Educação) - Faculdade de Educação, Universidade Estadual de Campinas, Campinas, 2000.

PARMENTIER, Emmanuel. C'est quoi un bon livre? Maxeville: Jean Lamour, 2009.

SERRES, Alain. Comment apprendre à ses parents à aimer les livres pour enfants. Ilustração de Bruno Heitz. SainteAmand-Montrond: Kouak, 2008.

SMITH, Frank. Compreendendo a leitura: uma análise psicolingüística da leitura e do aprender a ler. Porto Alegre: Artes Médicas, 1989.

VIGOSTKI, Lev Semenovich. A construção do pensamento e da linguagem. São Paulo: Martins Fontes, 2001.

NOTA
${ }^{1}$ O verbo apprendre em francês pode significar ensinar, aprender e saber.

Artigo recebido em julho 2013.

Aprovado em maio 2015. 